\title{
Metal(II) Coordination Polymers Derived from Mixed 4-Imidazole Ligands and Carboxylates: Syntheses, Topological Structures, and Properties
}

\author{
Wei-Dong Li ${ }^{1}$, Jia-Le Li ${ }^{1}$, Xing-Zhe Guo ${ }^{1}$, Zhi-You Zhang ${ }^{1}$ and Shui-Sheng Chen ${ }^{1,2, *} \mathbb{C}$ \\ 1 School of Chemistry and Chemical Engineering, Fuyang Normal University, Fuyang 236041, China; \\ weidongli2018@163.com (W.-D.L.); lijiale_lj1@163.com (J.-L.L.); zhujjj1993@126.com (X.-Z.G.); \\ fyzhiyouzhang@126.com (Z.-Y.Z.) \\ 2 Coordination Chemistry Institute, State Key Laboratory of Coordination Chemistry, Nanjing University, \\ Nanjing 210093, China \\ * Correspondence: chenss@fync.edu.cn; Tel.: +86-558-259-5836
}

Received: 6 May 2018; Accepted: 31 May 2018; Published: 6 June 2018

\begin{abstract}
Four new metal-organic coordination polymers $[\mathrm{Cu}(\mathrm{L})(\mathrm{mpa})] \cdot 3 \mathrm{H}_{2} \mathrm{O}(\mathbf{1}),[\mathrm{Co}(\mathrm{L})(\mathrm{mpa})] \cdot \mathrm{H}_{2} \mathrm{O}(2)$, $[\mathrm{Zn}(\mathrm{L})(\mathrm{mpa})] \cdot \mathrm{H}_{2} \mathrm{O}(3)$, and $\left[\mathrm{Cd}(\mathrm{L})(\mathrm{mpa})\left(\mathrm{H}_{2} \mathrm{O}\right)\right] \cdot \mathrm{H}_{2} \mathrm{O}$ (4) were synthesized by reactions of the corresponding metal(II) salts based on mixed ligands of 1,4-di(1H-imidazol-4-yl)benzene (L) and 4-methylphthalic acid $\left(\mathrm{H}_{2} \mathrm{mpa}\right)$, respectively. The structures of the complexes were characterized by elemental analysis, FT-IR spectroscopy, and single-crystal X-ray diffraction. Compound 1 exhibits a binodal 4-connected three dimensional (3D) architecture with $\left(6^{5} \cdot 8\right)-\mathrm{CdSO}_{4}$ topology, while complexes 2 and 3 are isostructural and have two-dimensional (2D) layer structure with $(4,4)$ sql topology based on the binuclear metal subunits. Complex 4 has the same 2D layer structure with $(4,4)$ sql topology as complexes 2 and 3, but the inclined interpenetration of parallel sets of layers result in the formation with $2 \mathrm{D}+2 \mathrm{D} \rightarrow 3 \mathrm{D}$ framework. The activated sample 1 shows selective $\mathrm{CO}_{2}$ uptake over $\mathrm{N}_{2}$. The photoluminiscent properties together with quantum yield (QY) and luminescence lifetime are also investigated for complexes 3 and $\mathbf{4}$ in the solid state at room temperature.
\end{abstract}

Keywords: coordination polymers; crystal structures; photoluminiscent property; adsorption property

\section{Introduction}

The design and construction of coordination polymers (CPs), and especially the subclass of metal-organic frameworks (MOFs), can be regarded nowadays as one of the most active research areas in recent years, not only due to their fascinating structural diversities, but also because of their interesting properties and potential applications as functional materials in many fields [1-10]. In principle, the assembly of MOFs can be influenced by several factors, such as the reaction condition, coordination geometry of the metal ions, nature of anions, flexibility, and coordination modes of the ligands, temperature, solvent, and so on [11-13]. Particularly, the key to design of MOFs with such outstanding features mainly depends on the judicious and rational choice of the bridging ligand because it greatly influences the molecular packing arrangement of the compound [14-17]. The N-donor ligands as well as the polycarboxylates, as two most commonly used organic linkers in the assembly of MOFs, have been widely designed and selected for their various coordination modes, and modifiable backbones. The $\mathrm{N}$-donor ligands with rod-type two-connector between the two terminal coordination groups, for example, 4, $4^{\prime}$-bipyridine(bpy), 1,2-bis(4-pyridyl)ethane(bpe), or their analogues, can be employed as 'pillars' together with the carboxylate ligand to meet the requirement of coordination geometries of metal ions in the assembly process [18-21]. More recently, 
we have designed a novel type of 4-imidazol-containing ligands with versatile coordination modes such as 1,4-di( $1 H$-imidazol-4-yl)benzene and 1,3,5-tri( $1 H$-imidazol-4-yl)benzene, and successfully constructed a series of porous metal-imidazolate complexes, which exhibit exceptional gas adsorption properties [22,23]. On the other hand, the polycarboxylates are the most extensively studied organic ligands in the construction of MOFs because the carboxylate groups have a high affinity for metal ions and may offer the possibility of incorporating more metal atoms into high-nuclearity clusters [24-26]. It is noteworthy that the polycarboxylates and $\mathrm{N}$-donors show different coordination preferences when coordinating with metal ions owing to the different electron configurations of $\mathrm{N}$ and $\mathrm{O}$ atoms $[27,28]$. Therefore, the mixed system including multi-N donor and carboxylate ligands can be effectively employed to build diverse coordination polymers due to their favorable compatibility. Following the mixed ligand strategy, we have focused our attention on the reactions of rigid 4-imidazole-containing ligands, together with different carboxylate ligands and different metal salts and synthesized a series of novel MOFs based on the $\mathrm{N}$ and $\mathrm{O}$ donor mixed spacers [29-32]. In this contribution, we focus our attention on the study on reactions of ligand 1,4-di $(1 \mathrm{H}$-imidazol-4-yl)benzene $(\mathrm{L})$ together with 4-methylphthalic acid $\left(\mathrm{H}_{2} \mathrm{mpa}\right)$ ligand and metal salts for the assembly of MOFs as an extension of our work. Herein, we report the synthesis and crystal structure of four new coordination polymers $[\mathrm{Cu}(\mathrm{L})(\mathrm{mpa})] \cdot 3 \mathrm{H}_{2} \mathrm{O}(\mathbf{1}),[\mathrm{Co}(\mathrm{L})(\mathrm{mpa})] \cdot \mathrm{H}_{2} \mathrm{O}(\mathbf{2}),[\mathrm{Zn}(\mathrm{L})(\mathrm{mpa})] \cdot \mathrm{H}_{2} \mathrm{O}(3)$, and $\left[\mathrm{Cd}(\mathrm{L})(\mathrm{mpa})\left(\mathrm{H}_{2} \mathrm{O}\right)\right] \cdot \mathrm{H}_{2} \mathrm{O}(4)$ obtained by reactions of $\mathrm{L}$ and $\mathrm{H}_{2} \mathrm{mpa}$, with corresponding metal salts under hydrothermal conditions, respectively. The scheme of coordination modes of $\mathrm{H}_{2} \mathrm{mpa}$ and L ligands in complexes 1-4 is exhibited in Scheme 1; the various coordination modes of L ligand is also described in detail [32].

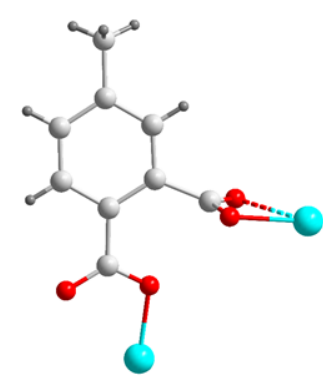

Complex 1

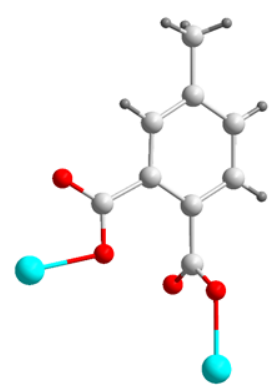

Complex 2-3

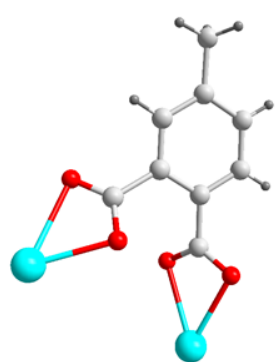

Complex 4

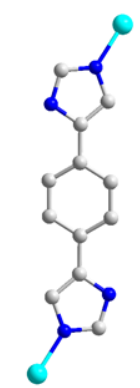

Complexes 1-4

Scheme 1. The scheme of coordination modes of $\mathrm{H}_{2}$ mpa and L ligands in 1-4.

\section{Materials and Methods}

\subsection{Materials and Physical Techniques}

The ligand 1,4-di(1H-imidazol-4-yl)benzene (L) was prepared as previously described [33]. Other chemical reagents and solvents were purchased commercially and were used as received without further purification. Elemental analyses were performed using a Perkin-Elmer 2400 elemental analyzer (Perkin-Elmer, Inc., Billerica, MA, USA). The infrared spectrum was recorded on a Nicolet Fourier Transform IR (Nicolet Instrument Inc., Madison, WI, USA), and a Nicolet MAGNA-IR 500 spectrometer (Nicolet Instrument Inc., Madison, WI, USA) in the range of $500-4000 \mathrm{~cm}^{-1}$ using the $\mathrm{KBr}$ disc technique. Thermogravimetric analyses (TGA) were performed on a computer-controlled Perkin-Elmer 7 Series/UNIX TGA7 analyzer (Perkin-Elmer, Inc., Billerica, MA, USA). Gas adsorption experiments were carried out on an Autosorb-iQ gas sorption instrument in Quantachrome Instruments U.S (Quantachrome, Delray Beach, FL, USA). The sample was activated by using the "outgas" function of the surface area analyzer (Quantachrome, Delray Beach, FL, USA) for $24 \mathrm{~h}$ at $160{ }^{\circ} \mathrm{C}$. Photoluminescence spectra for the solid samples were recorded with a HORIBA FluoroMax-4 fluorescence spectrophotometer at room temperature. The decay lifetimes were measured with 
an FLS920P fluorescence spectrometer (Edinburgh Instruments, Edinburgh, UK) in the solid state at room temperature.

\subsection{Synthesis of $[\mathrm{Cu}(\mathrm{L})(\mathrm{mpa})] \cdot 3 \mathrm{H}_{2} \mathrm{O}(\mathbf{1})$}

Reaction mixture of $\mathrm{L}(21.2 \mathrm{mg}, 0.1 \mathrm{mmol}), \mathrm{Cu}\left(\mathrm{NO}_{3}\right)_{2} \cdot 3 \mathrm{H}_{2} \mathrm{O}(24.2 \mathrm{mg}, 0.1 \mathrm{mmol}), \mathrm{H}_{2} \mathrm{mpa}(18.0 \mathrm{mg}$, $0.1 \mathrm{mmol})$, and $\mathrm{H}_{2} \mathrm{O}(8 \mathrm{~mL})$ was adjusted to $\mathrm{pH}=7$ with $0.5 \mathrm{~mol} \cdot \mathrm{L}^{-1} \mathrm{NaOH}$ solution. The mixture was then sealed into a $16 \mathrm{~mL}$ Teflon-lined stainless steel container and heated at $160{ }^{\circ} \mathrm{C}$ for 3 days. After cooling to the room temperature, green block crystals of $\mathbf{1}$ were collected by filtration and washed by water and ethanol for several times with a yield of $72 \%$. Anal. calcd. for $\mathrm{C}_{21} \mathrm{H}_{22} \mathrm{~N}_{4} \mathrm{O}_{7} \mathrm{Cu}(\%)$ : $\mathrm{C}, 49.85$; $\mathrm{H}, 4.38 ; \mathrm{N}, 11.07$. Found: C, 49.68; H, 4.49; N, 10.89. IR (KBr pellet, $\left.\mathrm{cm}^{-1}\right): 3427(\mathrm{~m}), 3140(\mathrm{~m}), 1567$ (vs), $1544(\mathrm{vs}), 1510(\mathrm{~m}), 1396(\mathrm{vs}), 1367(\mathrm{~m}), 1221(\mathrm{w}), 1141(\mathrm{~m}), 1077(\mathrm{~m}), 952(\mathrm{w}), 844(\mathrm{~s}), 808(\mathrm{~m}), 796(\mathrm{~m})$, $678(w), 647(w), 625(w), 535(w), 438(w)$.

\subsection{Synthesis of $[\mathrm{Co}(L)(m p a)] \cdot \mathrm{H}_{2} \mathrm{O}(2)$}

Complex 2 was obtained by the same hydrothermal procedure as that used for the preparation of 1 using $\mathrm{Co}\left(\mathrm{NO}_{3}\right)_{2} \cdot 6 \mathrm{H}_{2} \mathrm{O}(29.1 \mathrm{mg}, 0.1 \mathrm{mmol})$ instead of $\mathrm{Cu}\left(\mathrm{NO}_{3}\right)_{2} \cdot 3 \mathrm{H}_{2} \mathrm{O}$. After the reaction mixture was cooled down to room temperature, purple crystals of 2 were collected with a yield of $65 \%$. Anal. calcd. for $\mathrm{C}_{21} \mathrm{H}_{18} \mathrm{~N}_{4} \mathrm{O}_{5} \mathrm{Co}(\%)$ : C, 54.20; H, 3.90; N, 12.04. Found: C, 54.01; H, 4.12; N, 11.92. IR (KBr pellet, $\mathrm{cm}^{-1}$ ): 3488 (m), 3394 (m), 3145 (m), 2851 (m), 1645 (m), 1577(s), 1540 (vs.), 1496 (s), 1415 (vs.), 1362 (s), $1268(\mathrm{~m}), 1176(\mathrm{w}), 1166(\mathrm{w}), 1139(\mathrm{~s}), 1129(\mathrm{~s}), 1079(\mathrm{~m}), 970(\mathrm{~m}), 840(\mathrm{~s}), 823(\mathrm{~s}), 801(\mathrm{~m}), 685(\mathrm{w}), 650(\mathrm{~s})$, $637(\mathrm{~m}), 529(\mathrm{w}), 461(\mathrm{w})$.

\subsection{Synthesis of $[\mathrm{Zn}(\mathrm{L})(\mathrm{mpa})] \cdot \mathrm{H}_{2} \mathrm{O}(3)$}

Complex 3 was obtained by the same hydrothermal procedure as that used for the preparation of 1 using $\mathrm{Zn}\left(\mathrm{NO}_{3}\right)_{2} \cdot 6 \mathrm{H}_{2} \mathrm{O}(29.7 \mathrm{mg}, 0.1 \mathrm{mmol})$ instead of $\mathrm{Cu}\left(\mathrm{NO}_{3}\right)_{2} \cdot 3 \mathrm{H}_{2} \mathrm{O}$. After the reaction mixture was cooled down to room temperature, colorless crystals of 3 were collected with a yield of $72 \%$. Anal. calcd. for $\mathrm{C}_{21} \mathrm{H}_{18} \mathrm{~N}_{4} \mathrm{O}_{5} \mathrm{Zn}(\%)$ : C, 53.46; H, 3.85; N, 11.88. Found: C, 53.31; H, 3.96; N, 11.42. IR (KBr pellet, cm ${ }^{-1}$ ): 3485 (m), 3390 (w), 3134 (m), 2852 (m), 1647 (w), 1587 (vs.), 1546 (vs.), 1479 (s), 1415 (vs.), 1356 (s), 1270 (w), 1140 (s), 1081 (m), 971 (m), 949 (m), 840 (s), 799 (s), 685 (w), 649 (s), 529 (m), $476(\mathrm{w}), 485(\mathrm{~m})$.

\subsection{Synthesis of $\left[\mathrm{Cd}(\mathrm{L})(\mathrm{mpa})\left(\mathrm{H}_{2} \mathrm{O}\right)\right] \cdot \mathrm{H}_{2} \mathrm{O}(4)$}

A mixture of $\mathrm{CdCl}_{2} \cdot 2.5 \mathrm{H}_{2} \mathrm{O}(22.8 \mathrm{mg}, 0.1 \mathrm{mmol}), \mathrm{L}(21.0 \mathrm{mg}, 0.1 \mathrm{mmol}), 4-\mathrm{H}_{2} \mathrm{mpa}(18.0 \mathrm{mg}$, $0.1 \mathrm{mmol})$ and $\mathrm{NaOH}(12.0 \mathrm{mg}, 0.3 \mathrm{mmol})$ in $10 \mathrm{~mL} \mathrm{H}_{2} \mathrm{O}$ was sealed in a $16 \mathrm{ml}$ Teflon lined stainless steel container and heated at $180^{\circ} \mathrm{C}$ for $3 \mathrm{~d}$. Brown block crystals of 4 were collected in $68 \%$ yield after being washed with water and ethanol several times. Anal. calcd for $\mathrm{C}_{21} \mathrm{H}_{20} \mathrm{~N}_{4} \mathrm{O}_{6} \mathrm{Cd}(\%)$ : C, 46.99; H, 3.76; N, 10.44. Found: C, 46.81; H, 3.90; N, 11.42. IR (KBr pellet, $\left.\mathrm{cm}^{-1}\right)$ : 3135 (m), $2362(\mathrm{w}), 1593$ (m), 1552 (vs), 1505 (m), 1395 (vs), $1270(\mathrm{w}), 1221$ (w), $1172(\mathrm{w}), 1138(\mathrm{~s}), 1074(\mathrm{~m}), 945(\mathrm{~s}), 842$ (s), $800(\mathrm{~m})$, $719(\mathrm{w}), 680(\mathrm{w}), 649(\mathrm{~m}), 618(\mathrm{~m}), 563(\mathrm{w}), 416(\mathrm{w})$.

\subsection{Crystallographic Data Collection and Refinements}

The data collections for 1-4 were carried out on a Bruker Smart Apex CCD (Charge Coupled Device) area-detector diffractometer using graphite-monochromated Mo K $\alpha$ radiation $(\lambda=0.71073 \AA)$ at $23(2){ }^{\circ} \mathrm{C}$. The diffraction data was integrated by using the SAINT program [34]. Semi-empirical absorption corrections were applied using the SADABS program [35]. The structures were solved by direct methods and all nonhydrogen atoms were refined anisotropically on $F^{2}$ by the full-matrix least-squares technique using the SHELXL-97 crystallographic software package [36]. The hydrogen atoms were generated geometrically. The details of the crystal parameters, data collection, and refinements for the complexes are summarized in Table 1, selected bond lengths and angles with their 
estimated standard deviations are listed in Table S1. The hydrogen atoms of solvent water molecules in $\mathbf{1}$ and $\mathbf{2}$ were found directly from the differential Fourier map. All the other hydrogen atoms were generated geometrically except that the hydrogen atoms that were part of water molecules were not identified. Crystal data and details of the data collection and structure refinements for 1-4 are summarized in Table 1. CCDC (Cambridge Crystallographic Data Centre)-1836731, 1836732, 1836733 and 1836734 for $\mathbf{1}, \mathbf{2}, \mathbf{3}$, and 4, respectively. These data can be obtained free of charge at www.ccdc.cam. ac.uk/conts / retrieving.html or from the Cambridge Crystallographic Data Centre, 12, Union Road, Cambridge CB2 1EZ, UK; fax: (internet)+44-1223/336-033; email: deposit@ccdc.cam.ac.uk.

Table 1. Crystallographic data and structure refinement details for complexes 1-4.

\begin{tabular}{|c|c|c|c|c|}
\hline & 1 & 2 & 3 & 4 \\
\hline Empirical formula & $\mathrm{C}_{21} \mathrm{H}_{22} \mathrm{~N}_{4} \mathrm{O}_{7} \mathrm{Cu}$ & $\mathrm{C}_{21} \mathrm{H}_{18} \mathrm{~N}_{4} \mathrm{O}_{5} \mathrm{Co}$ & $\mathrm{C}_{21} \mathrm{H}_{18} \mathrm{~N}_{4} \mathrm{O}_{5} \mathrm{Zn}$ & $\mathrm{C}_{21} \mathrm{H}_{20} \mathrm{~N}_{4} \mathrm{O}_{6} \mathrm{Cd}$ \\
\hline Formula weight & 505.97 & 465.32 & 471.75 & 536.78 \\
\hline Temperature/K & $296(2)$ & 296(2) & 296(2) & $296(2)$ \\
\hline Crystal system & Triclinic & Monoclinic & Monoclinic & Orthorhombic \\
\hline Space group & $P-1$ & $P 2{ }_{1} / \mathrm{n}$ & $P 2_{1} / \mathrm{n}$ & Pbca \\
\hline$a / \AA$ & $10.1312(4)$ & $11.6926(10)$ & $11.8456(13)$ & $10.8135(5)$ \\
\hline$b / \AA$ & $10.7982(4)$ & $16.4817(14)$ & $16.6553(18)$ & $13.8757(7)$ \\
\hline$c / \AA$ & $11.7947(5)$ & 11.8661(10) & $11.8476(11)$ & $27.2928(12)$ \\
\hline$\alpha /^{\circ}$ & $105.8050(10)$ & 90 & 90 & 90 \\
\hline$\beta /^{\circ}$ & $113.9580(10)$ & $112.9970(10)$ & $114.445(3)$ & 90 \\
\hline$\gamma /{ }^{\circ}$ & $97.6470(10)$ & 90 & 90 & 90 \\
\hline$V\left(\AA^{3}\right)$ & $1090.14(7)$ & $2105.0(3)$ & $2127.9(4)$ & 4095.1(3) \\
\hline $\mathrm{Z}$, Dcalc $/\left(\mathrm{Mg} / \mathrm{m}^{3}\right)$ & $2,1.541$ & $4,1.468$ & $4,1.466$ & $8,1.728$ \\
\hline$F(000)$ & 522 & 956 & 960 & 2128 \\
\hline$\theta$ range $/^{\circ}$ & $2.97-27.59$ & $2.07-27.46$ & $2.25-26.02$ & $2.40-26.02$ \\
\hline Reflections collected & 22902 & 12581 & 25416 & 46938 \\
\hline Independent reflections & 5040 & 4738 & 4166 & 4030 \\
\hline Goodness-of-fit on $F^{2}$ & 1.053 & 1.019 & 1.059 & 1.096 \\
\hline$R_{1}[I>2 \sigma(I)]^{\mathrm{a}}$ & 505.97 & 465.32 & 471.75 & 536.78 \\
\hline$w R_{2}[I>2 \sigma(I)]^{\mathrm{b}}$ & $296(2)$ & $296(2)$ & $296(2)$ & $296(2)$ \\
\hline
\end{tabular}

\section{Results}

\subsection{Structural Descriptions}

\subsubsection{Structure of $[\mathrm{Cu}(\mathrm{L})(\mathrm{mpa})] \cdot 3 \mathrm{H}_{2} \mathrm{O}(\mathbf{1})$}

The result of X-ray diffraction analysis revealed that complex $\mathbf{1}$ crystallizes in a triclinic form with space group of P-1 (Table 1), and the asymmetric unit consists of two kinds of $\mathrm{Cu}$ (II) atoms, namely, both of $\mathrm{Cu}$ (II) atoms sitting on a special position with a half of occupancy, two halves of the L ligand, one completely deprotonated $\mathrm{mpa}^{2-}$ ligand, and three free water molecules as shown in Figure $1 \mathrm{a}$. The Cu1 atom is four-coordinated in square-planar coordination geometry, which is surrounded by two carboxylate oxygen atoms $(\mathrm{O} 1, \mathrm{O} 1 \mathrm{~A})$ from two individual $\mathrm{mpa}^{2}$ - ligands, and two nitrogen atoms (N1, N1A) from two different L ligands. The Cu2 atom exhibits a distorted octahedral environment in which the basal plane consists of the four $\mathrm{O}$ atoms $(\mathrm{O} 3, \mathrm{O} 4, \mathrm{O} 3 \mathrm{~B}$, and $\mathrm{O} 4 \mathrm{~B})$ from carboxylate groups of $\mathrm{mpa}^{2}$ - ligands while the axial position is filled by two symmetrical 4-imidazolyl N atoms (N3 and N3B) from two different L ligands. When the connections via the L ligands (containing N1 and N2 atoms) are ignored, the $\mathrm{Cu}(\mathrm{II})$ atoms are linked through the other L ligands (containing N3 and N4 atoms) together with $\mathrm{mpa}^{2-}$ ligands, leading to the formation of a two-dimensional (2D) coordination network (Figure $1 b$ ). The just ignored L ligands acts as two-connector pillars to link $\mathrm{Cu}(\mathrm{II})$ atoms of adjacent 2D nets to form three-dimensional (3D) pillar-layered frameworks with void channels along the $c$ axis (Figure 1c). The total void value of the channel without water guests is estimated (by PLATON) [37] to be $187.1 \AA$, approximately $17.2 \%$ of the total crystal volume of $1090.1 \AA$. Topological analysis was 
carried out to analyze the structure of 1 . As discussed above, each $\mathrm{mpa}^{2-}$ and L ligand link two $\mathrm{Cu}$ (II) atoms, respectively, and accordingly, the $\mathrm{mpa}^{2-}$ and $\mathrm{L}$ can be regarded as 2-connected nodes, respectively. As for $\mathrm{Cu} 1$ and $\mathrm{Cu} 2$ atoms, both of them in turn link two mpa ${ }^{2-}$ and two L ligands; hence, they can be treated as 4-connectors. According to the simplification principle, the resulting structure of the complex 1 is a bimodal $(4,4)$-connected net with a Schläfli symbol $\left(6^{5} \cdot 8\right)$, which has been referred to by $\mathrm{O}^{\prime}$ Keeffe and Wells as the $\mathrm{CdSO}_{4}$ notation (Figure 1d) [38].
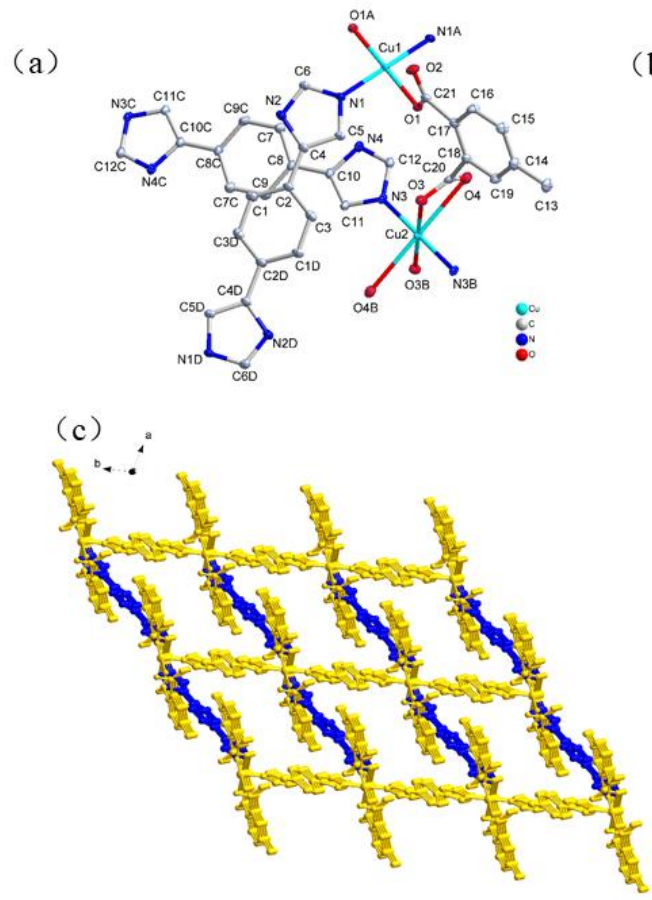

(b)

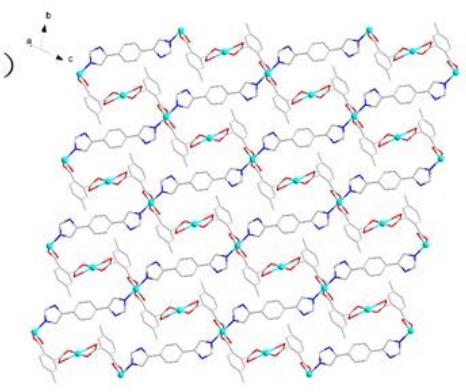

(d)

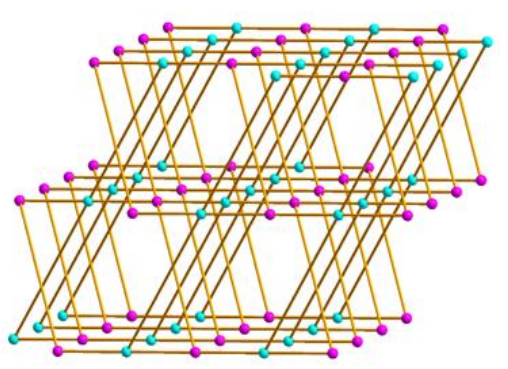

Figure 1. (a) The coordination environment of the $\mathrm{Cu}$ (II) atoms in $\mathbf{1}$ with the ellipsoids drawn at the $30 \%$ probability level. The hydrogen atoms and free water molecules are omitted for clarity. Symmetry code: A -x, 2 - y, 1 - z, B -x, 2 - y, -z; (b) 2D network of 1; (c) 3D structure of 1 constructed from the 2D networks (yellow) pillared by L ligands (blue); (d) schematic representation of the binodal $(4,4)$-connected 3D framework of 1 with $\mathrm{CdSO}_{4}$ topology with Schläfli symbol $\left(6^{5} \cdot 8\right)$.

\subsubsection{Structures of $[\mathrm{Co}(\mathrm{L})(\mathrm{mpa})] \cdot \mathrm{H}_{2} \mathrm{O}(2)$ and $[\mathrm{Zn}(\mathrm{L})(\mathrm{mpa})] \cdot \mathrm{H}_{2} \mathrm{O}(3)$}

As $\mathrm{Co}\left(\mathrm{NO}_{3}\right)_{2} \cdot 6 \mathrm{H}_{2} \mathrm{O}$ and $\mathrm{Zn}\left(\mathrm{NO}_{3}\right)_{2} \cdot 6 \mathrm{H}_{2} \mathrm{O}$, instead of $\mathrm{Cu}\left(\mathrm{NO}_{3}\right)_{2} \cdot 3 \mathrm{H}_{2} \mathrm{O}$, was used in the reaction of $\mathbf{1}$, respectively, $\mathbf{2}$ and $\mathbf{3}$ with different structures were isolated. Complexes $\mathbf{2}$ and $\mathbf{3}$ crystallize in the same monoclinic $\mathrm{P} 2_{1} / \mathrm{n}$ space group with similar cell parameters (Table 1 ), and the results of $X$-ray crystallographic analysis indicate that they are isomorphous and isostructural. Thus, as a typical example, only the structure of $\mathbf{2}$ is described here in detail. The asymmetric unit of 2 contains one unique $\mathrm{Co}(\mathrm{II})$ atom coordinated by two nitrogen atoms (N1 and N3B) from two different $\mathrm{L}$ ligands and two carboxylate oxygen atoms (O1 and O3A) from two different $\mathrm{mpa}^{2-}$ ligands, thereby forming a four-coordinated tetrahedral coordination geometry with a $\mathrm{N}_{2} \mathrm{O}_{2}$ donor set (Figure 2a). The Co-O bond lengths are 1.974(19) and 2.002(18) $\AA$, and $\mathrm{Co}-\mathrm{N}$ ones are 2.036(2) and 2.015(2) $\AA$ (Table S1), which are consistent with the reported four-coordinated $\mathrm{Co}(\mathrm{II})$ complexes with $\mathrm{O}$ and $\mathrm{N}$ donors [39]. The mpa ${ }^{2-}$ ligand connects two Co(II) atoms using its two adjacent carboxylate groups with $\mu_{1}-\eta^{1}: \eta^{0}$-monodentate coordination mode. Interestingly, four carboxylate groups from two different mpa ${ }^{2-}$ ligands together with two $\mathrm{Co}(\mathrm{II})$ atoms form a $\mathrm{Co}_{2}(\mathrm{COO})_{2}$ binuclear SBU with a Co … Co distance of $5.45 \AA$. Each such SBU links four identical ones through four L ligands via Co-N coordination leading to formation of a $2 \mathrm{D}$ network with $(4,4)$ sql topology by taking the binuclear SBUs as 4-connecting nodes and the L ligands as linkers (Figure $2 b, c)$. The 2D layers are further linked 
together via extensive intermolecular $\mathrm{N}-\mathrm{H} \cdots \mathrm{O}, \mathrm{O}-\mathrm{H} \cdots \mathrm{O}$ and $\mathrm{C}-\mathrm{H} \cdots \mathrm{O}$ hydrogen bonds to generate a 3D structure (Figure 2d).

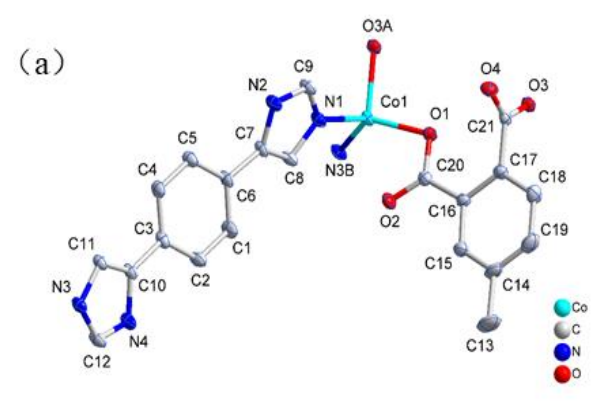

(c)

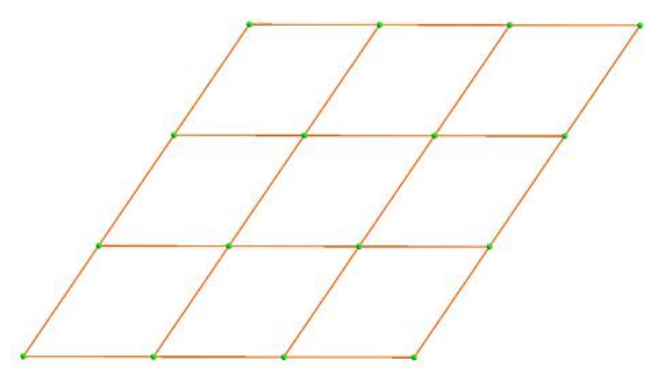

(b)

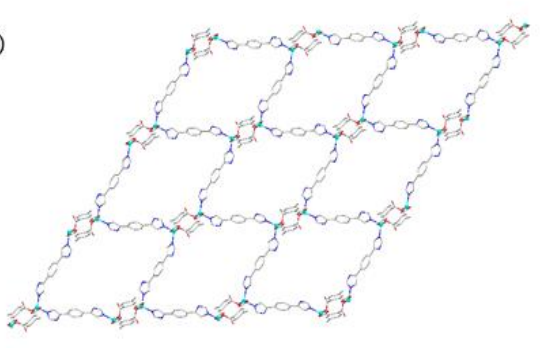

(d)

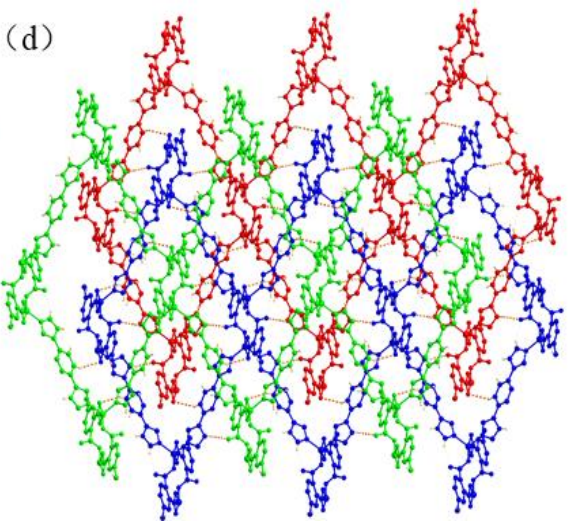

Figure 2. (a) The coordination environment of the Co(II) atoms in 2 with the ellipsoids drawn at the $30 \%$ probability level. The hydrogen atoms and free water molecules are omitted for clarity. Symmetry code: A - x, 2 - y, 2 - z, B - $0.5-x, 0.5+y, 0.5-z$; (b) 2D network of 2; (c) schematic representation of 2D network with $(4,4)$ topology in complex 2 ; (d) 3D framework of 2 linked by hydrogen bonds indicated by a dashed line (different color represents 2D layer).

\subsubsection{Structure of $\left[\mathrm{Cd}(\mathrm{L})(\mathrm{mpa})\left(\mathrm{H}_{2} \mathrm{O}\right)\right] \cdot \mathrm{H}_{2} \mathrm{O}(4)$}

To further investigate the effect of metal salt, the $\mathrm{Cu}\left(\mathrm{NO}_{3}\right)_{2} \cdot 3 \mathrm{H}_{2} \mathrm{O}$ was changed to $\mathrm{CdCl}_{2} \cdot 2.5 \mathrm{H}_{2} \mathrm{O}$, and complex 4 with a different structure was obtained. The asymmetric unit of $\mathbf{1}$ contains one $\mathrm{Cd}(\mathrm{II})$ ion, one $\mathrm{L}$ ligand, one $\mathrm{mpa}^{2-}$ ligand, one coordinated, and one lattice water molecules. The Cd1 atom is seven-coordinated by two $\mathrm{N}$ atoms $(\mathrm{N} 1, \mathrm{~N} 3 \mathrm{~B})$ from two different $\mathrm{L}$ ligands, four $\mathrm{O}$ atoms $(\mathrm{O} 1, \mathrm{O} 2$, $\mathrm{O} 3 \mathrm{~A}$, and $\mathrm{O} 4 \mathrm{~A}$ ) from two pairs of chelating carboxylate groups of two different $\mathrm{mpa}^{2-}$ ligands and one $\mathrm{O}$ atom (O5) from coordinated water molecule (Figure 3a). The average $\mathrm{Cd} 1-\mathrm{O}$ and $\mathrm{Cd} 1-\mathrm{N}$ distances are 2.462(3) and 2.293(3) $\AA$, respectively, and the coordination angles around Cd1 varies from 53.39(9) to $169.70(10)^{\circ}$ (Table S1). Similar to the complexes 2 and 3, both of adjacent carboxylate groups from the mpa ${ }^{2-}$ ligand connect two Cd(II) atoms in $\mu_{1}-\eta^{1}: \eta^{1}$-chelating coordination mode, and four carboxylate groups from two different $\mathrm{mpa}^{2-}$ ligand connect two $\mathrm{Cd}(\mathrm{II})$ atoms to form a $\mathrm{Cd}_{2}(\mathrm{COO})_{2}$ binuclear SBU with Cd...Cd distance of $5.24 \AA$. The binuclear SBUs is employed as a 4-connecting node to connect other four identical ones by four linear L ligands, forming the 2D network with $(4,4)$ topology by taking the binuclear SBUs as 4-connecting nodes and the L ligands as linkers (Figure 3b,c). In 4, two L ligands and two Cd(II) ions form a macrocycle through the coordination bonds, where the lateral distances of $\mathrm{Cd}_{2}(\mathrm{COO})_{2}$ binuclear SBU is $18.74 \AA$, and the through-space apertures within a single layer submotif measure $13.88 \times 34.82 \AA$, with the angles among SBU nodes of $43.45^{\circ}$ and $136.55^{\circ}$. Thus, the shape of this macrocycle is a rhombus. The large rectangular windows within the layers permit mutual inclined interpenetration of parallel sets of layers, forming the $2 \mathrm{D}+2 \mathrm{D} \rightarrow 3 \mathrm{D}$ framework (Figure 3d,e) [40,41]. 


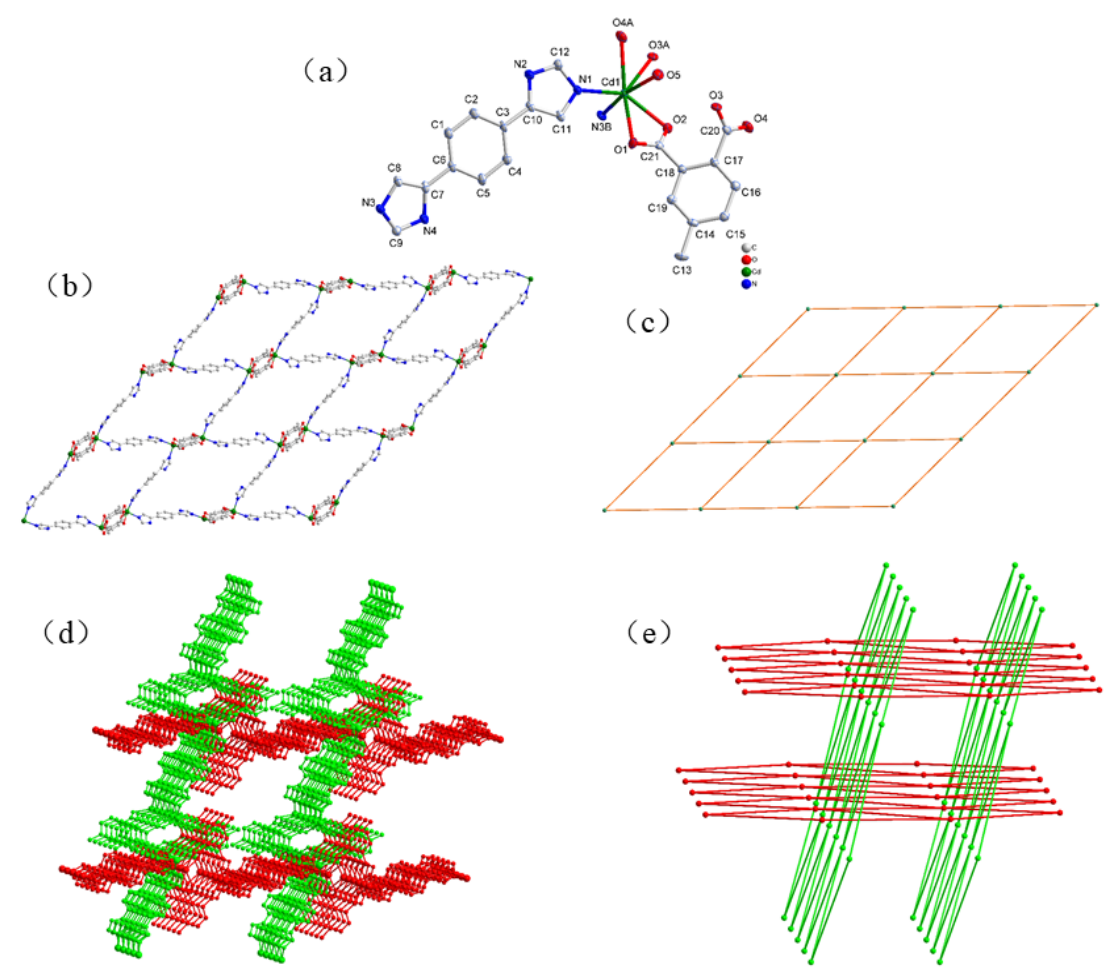

Figure 3. (a) The coordination environment of the Cd(II) atoms in 4 with the ellipsoids drawn at the $30 \%$ probability level. The hydrogen atoms and water molecules are omitted for clarity. Symmetry code: A $1-\mathrm{x},-0.5+\mathrm{y}, 0.5-\mathrm{z}, \mathrm{B}-\mathrm{x},-\mathrm{y}, 1-\mathrm{z}$; (b) 2D network of 4; (c) schematic representation of 2D network with $(4,4)$ topology in complex 4 ; (d) mutual interpenetration of parallel sets of layers in 4 (different color represents 2D layer); (e) schematic illustration of 2D $+2 \mathrm{D} \rightarrow 3 \mathrm{D}$ mutual inclined interpenetration in 4 (different color represents schematic illustration of 2D).

\subsection{Thermal Analyses and X-ray Powder Diffraction Analyses}

Thermogravimetric analysis (TGA) was employed on complexes 1-4 in order to ascertain the stability, and the results are shown in Supporting Information Figure S1. A total weight loss of $10.25 \%$ was observed for 1 in the temperature range of $75-140{ }^{\circ} \mathrm{C}$, which is attributed to the loss of three lattice water molecules (calc. $10.67 \%$ ), and the decomposition of the residue occurred at $235{ }^{\circ} \mathrm{C}$. For 2, the first weight loss of $3.62 \%$ in $200-275^{\circ} \mathrm{C}$ indicated the exclusion of one free lattice water molecule (calc. $3.87 \%$ ), and the residue is stable up to about $330{ }^{\circ} \mathrm{C}$. A total weight loss of $3.95 \%$ was observed for 3 in the temperature range of $180-230{ }^{\circ} \mathrm{C}$, which is attributed to the loss of three coordinated and one free water molecules (calc. $3.82 \%$ ), and the residue is stable up to about $260^{\circ} \mathrm{C}$. A total weight loss of $6.55 \%$ was observed for 4 in the temperature range of $50-105{ }^{\circ} \mathrm{C}$, which is attributed to the loss of water molecules (calc. 6.71\%), and the residue is stable up to about 305 ${ }^{\circ} \mathrm{C}$. The pure phase of coordination polymers was proved by the powder X-ray diffraction (PXRD), where the patterns of, as-synthesized, 1-4 are consistent with the corresponding simulated ones (Figure S3), indicating the phase purity of the sample. The further stability information about the porous structure is required in order to make gas adsorption measurements for the porous materials of 1 . After heating of 1 at $160^{\circ} \mathrm{C}$ for $24 \mathrm{~h}$ in vacuum, the guest water molecules were removed. The PXRD patterns at varied temperature show that the framework of $\mathbf{1}$ is retained (Figure S2), indicating that complex 1 has permanent porosity after evacuation.

\subsection{Diffuse Reflectance Spectra}

The solid state diffuse reflectance UV-Vis (Ultraviolet-visible) spectra at room temperature were recorded for the as-synthesized samples of 1-4 (Figure 4a). To study the conductivity of the 
complexes, the solid state diffuse reflectance UV-Vis spectrum of complexes were applied to calculate the band gap $E_{g}$, which was determined as the intersection point between the energy axis (hv) and the line derived from the linear portion of the absorption edge in a plot of the $\mathrm{K}-\mathrm{M}$ (Kubelka-Munk) theory F vs. the incident photon energy hv [42]. UV-visible spectra of coordination polymers 1-2 have absorptions in the UV region as well as in the visible region, absorptions in the UV region are due to ligand, and in the visible region are due to $d-d$ transitions $\left({ }^{2} E_{g}\right.$ to $\left.{ }^{2} T_{2 g}\right)$ of copper(II) compounds [43,44]. Coordination polymers 3 and $\mathbf{4}$ shows an absorption in UV-region due to a ligand, and it does not absorb in the visible region because of the $A_{1 g}$ ground state. As shown in Figure $4 b$, the optical band gaps obtained by extrapolation of the linear portion of the diffuse reflectance spectra are estimated as 3.32, 3.55, 3.91, and $3.90 \mathrm{eV}$ for complexes 1-4, respectively, indicating the existence of optical direct band gap and the characteristic of semiconductivity, which have potential application in the field of semiconductor [45-47].

(a)

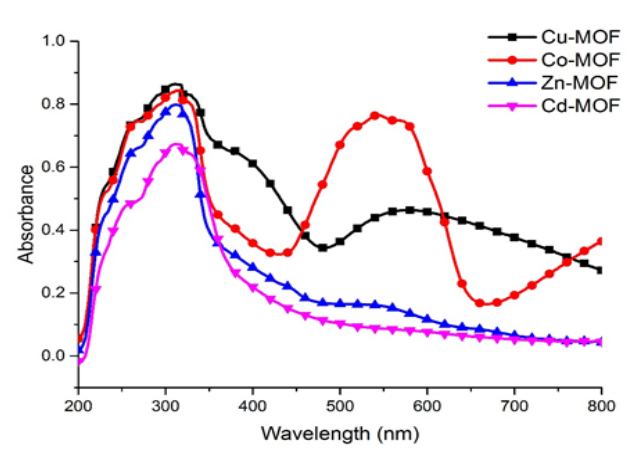

(b)

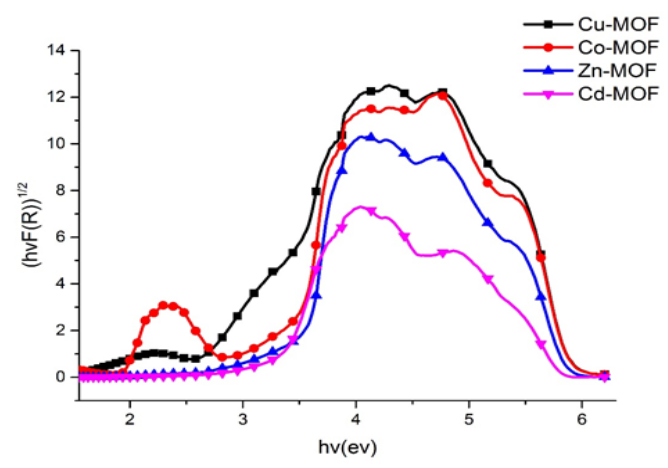

Figure 4. (a) The solid-state diffuse reflectance UV-Vis spectra for the complexes 1-4; (b) The result of the right picture was treated with the Kubelka-Munk function.

\subsection{Photoluminescent Property}

Inorganic-organic hybrid coordination polymers have been reported to have the ability to adjust the emission wavelength of organic materials through incorporation of metal centers, especially for $\mathrm{d}^{10}$ metal centers $[48,49]$. The fluorescence properties of the crystalline materials 3 and 4 , as well as the free L ligand have been investigated in the solid state, as depicted in Figure 5. The free $\mathrm{L}$ ligand shows emission band at $450 \mathrm{~nm}$ upon excitation at $370 \mathrm{~nm}$, which may be attributed to $\pi^{*}$ $\rightarrow \pi$ transition of the intraligands [50,51]. As previously reported [52,53], the fluorescence emission of solid-state benzenecarboxylate ligands can be assigned to the $\pi^{*} \rightarrow \mathrm{n}$ transition. Comparatively, the fluorescent emission of benzene-dicarboxylate ligands resulting from the $\pi^{*} \rightarrow \mathrm{n}$ transition is weak in comparison to that of the $\pi^{*} \rightarrow \pi$ transition of the conjugated aromatic ligands such as the $\mathrm{L}$ ligand, so benzene-carboxylate ligands almost have little contribution to the fluorescent emission of $\mathrm{d}^{10}$ complexes [54,55]. Figure 6 shows that compounds 3 and 4 exhibit blue photoluminescence with emission maxima at 446 and $424 \mathrm{~nm}$ upon excitation at 370 and $357 \mathrm{~nm}$, respectively. In contrast to the free L ligand, the emission bands of complexes 3 and 4 are $4 \mathrm{~nm}$ red-shifted and $22 \mathrm{~nm}$ blue-shifted respectively. The emissions of these complexes may be assigned to the cooperative effects of intraligand transition and differences in the coordination environments [56,57]. In addition, it is noteworthy that the enhancement of luminescence for the complex 4 compared with the free ligand and 3 under the same conditions may mainly originate from the coordination interactions between the metal Cd(II) atom and the ligand, which enhanced its conformational rigidity and then decreased the nonradiative energy loss [58]. 


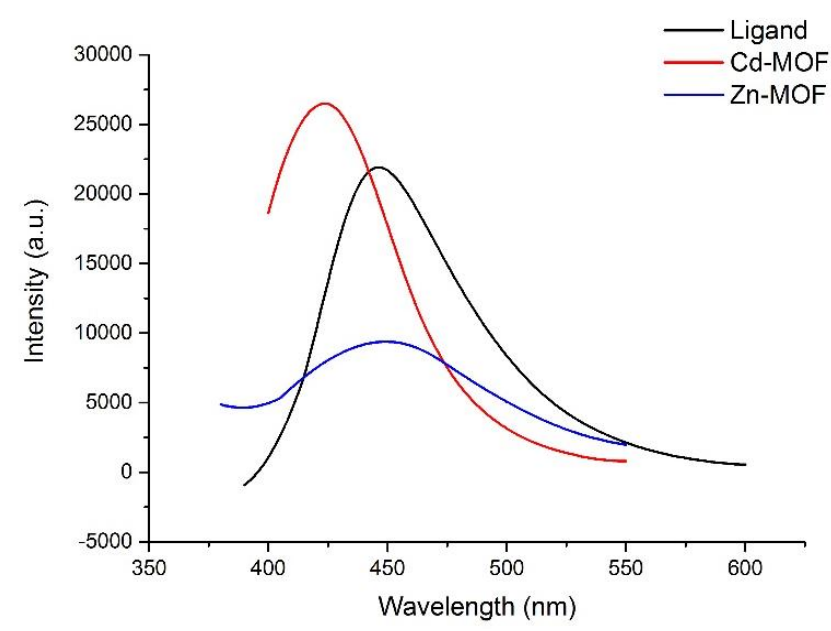

Figure 5. Emission spectra of complexes 3 and 4 together with L ligand.

In order to further study the luminescence properties, study of the corresponding quantum yield (QY) and decay lifetimes were carried out for compounds 3 and 4 together with L ligand. The QY values of compounds $4\left(\mathrm{QY}_{4}=5.12 \%\right)$ was higher than complex $3\left(\mathrm{QY}_{3}=0.27 \%\right)$. The high QY values of compounds 4 is probably attributed to the immobilization of the L ligand as it is strongly coordinated to metal Cd(II) ions that effectively increase the rigidity of the ligands and to the low-dimensional structure with a $\pi$-conjugated system that decreases the molecular band gap $[59,60]$. In addition, the luminescence decay curves can be fitted by an exponential function as $I(\mathrm{t})=\mathrm{A} \exp (-t / \tau)$. The longest luminescence lifetime of compound 4 reaches $178 \mathrm{~ns}$, higher than complex 3, but much shorter than the ones resulting from a triplet state $\left(>10^{-3} \mathrm{~s}\right)$, so the emissions should arise from a singlet state [61,62]. Therefore, the good photoluminescence property of 4 indicates that it could be potentially used as luminescent material.

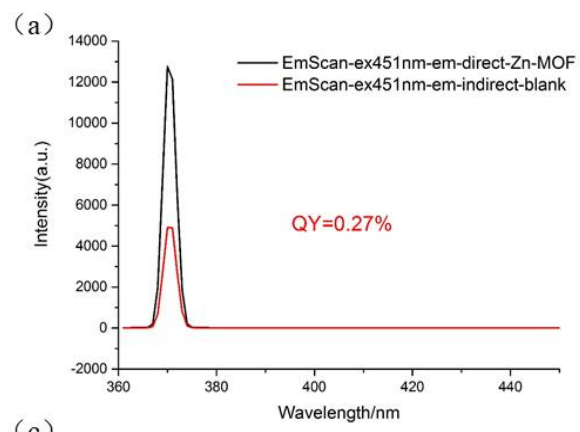

(c)
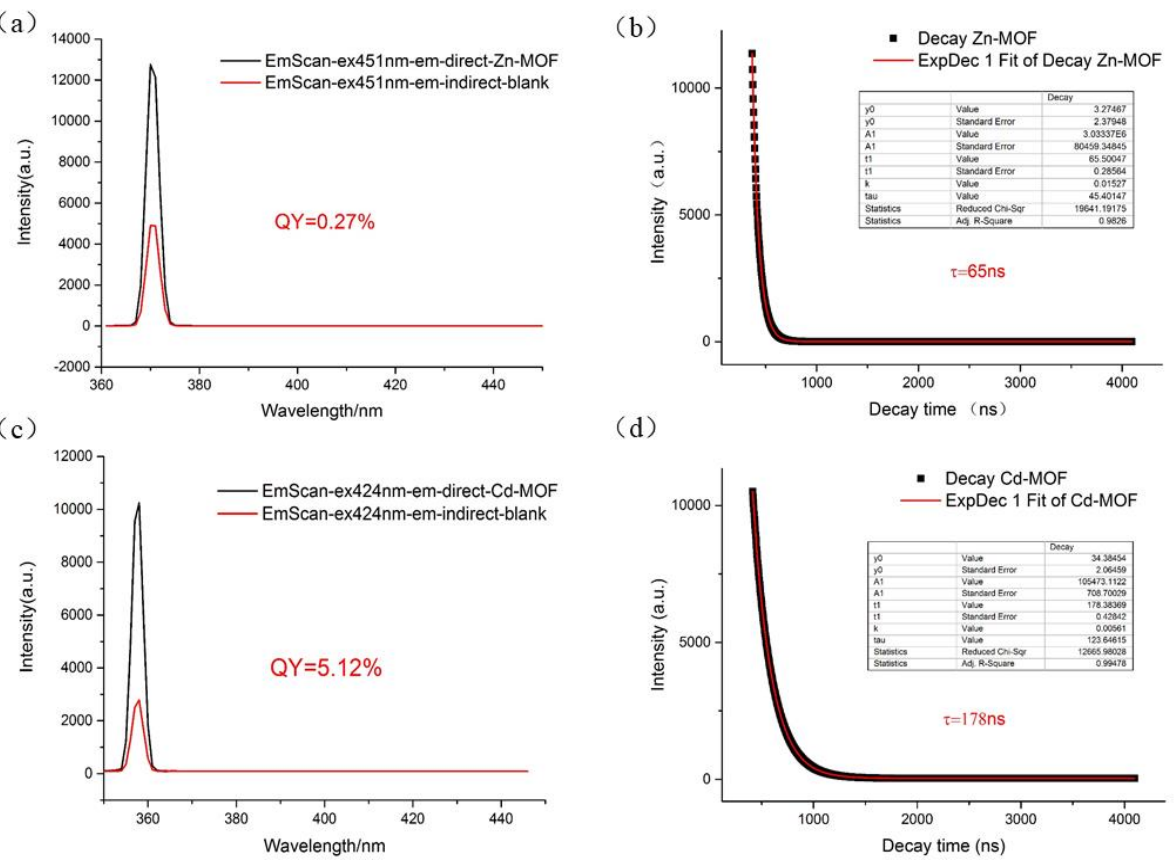

(d)

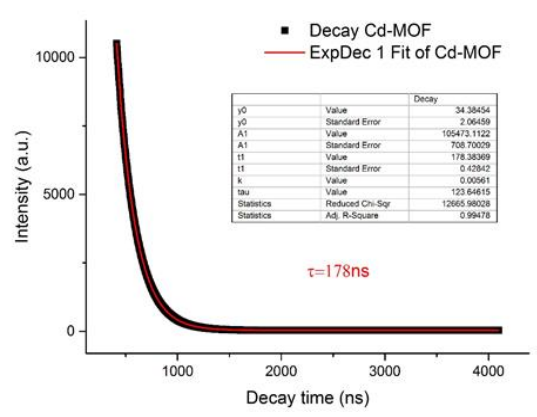

Figure 6. The QY and decay curves of compounds 3 (a and b) and 4 (c and d). 


\subsection{Gas Sorption Property}

Crystal structure analysis shows that the 3D framework structure in $\mathbf{1}$ has $17.2 \%$ void volume resided by lattice water molecules. The framework of $\mathbf{1}$ can maintain its porous framework after evacuation, as can be confirmed by TGA and PXRD measurements (Figures S1 and S2). The desolvated solid with $17.2 \%$ free void volume in $\mathbf{1}$ can be employed as microporous material to adsorb gases. Therefore, a further study was subsequently undertaken to investigate the gas adsorption property of the desolvated sample $\mathbf{1}^{\prime}$. The $\mathrm{N}_{2}$ and $\mathrm{CO}_{2}$ sorption isotherms in Figure 7 shows the microporous material of $\mathbf{1}^{\prime}$ exhibit $\mathrm{CO}_{2}$ adsorption property, but no $\mathrm{N}_{2}$ uptake was observed at $77 \mathrm{~K}$ for $\mathbf{1}^{\prime}$ in the low-pressure region, and only shows $28.73 \mathrm{~cm}^{3} / \mathrm{g}$ at $1 \mathrm{~atm}$, which exhibits type III sorption profiles, suggesting that only surface adsorption occurs [63]. The $\mathrm{CO}_{2}$ gas adsorption isotherms of $\mathbf{1}^{\prime}$ display a steep rise at the relative low pressure region which can be categorized as reversible type-I, exhibiting a typical permanent microporosity, while the $\mathrm{CO}_{2}$ gas desorption isotherm of $\mathbf{1}^{\prime}$ shows pronounced hysteresis as illustrated in Figure 7. The adsorption amount, $9.7 \mathrm{wt} \%$ of $\mathrm{CO}_{2}$ at $195 \mathrm{~K}$ and $1 \mathrm{~atm}$ $\left(49.71 \mathrm{~cm}^{3} / \mathrm{g}\right.$ at standard temperature and pressure (STP)), corresponds to $1.1 \mathrm{CO}_{2}$ molecule per formula unit of the solid $\mathbf{1}^{\prime}$. The distinct difference of adsorption capacity between $\mathrm{CO}_{2}$ and $\mathrm{N}_{2}$ for $\mathbf{1}^{\prime}$ must be mainly associated with the smaller kinetic diameters of $\mathrm{CO}_{2}(3.3 \AA)$ than that of $\mathrm{N}_{2}(3.64 \AA)$, and the Quadrupole Moment of $\mathrm{CO}_{2}\left(-1.4 \times 10^{-39} \mathrm{~cm}^{2}\right)$ is the important factor that affects the distinct difference in adsorption capacity $[64,65]$.

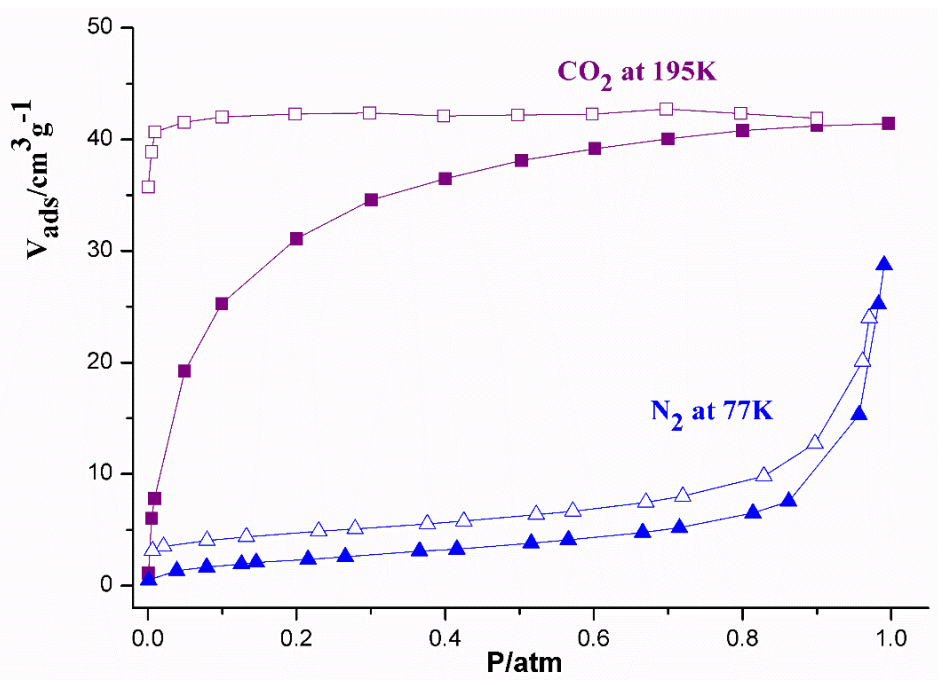

Figure 7. Gas adsorption isotherms of $\mathbf{1}^{\prime}$ : filled shape, adsorption; open shape, desorption.

\section{Conclusions}

The coordination polymers based on mixed multi-N-donor and polycarboxylate auxiliary ligands were synthesized by reactions of the different metal salts under hydrothermal methods. The nature of different metal centers are key factors to construct diverse frameworks. The complex 1 is a rare binodal $(4,4)$-connected 3D CdSO${ }_{4}$ architecture. Complexes $\mathbf{2}$ and $\mathbf{3}$ are isomorphous and isostructural, possessing 2D networks with $(4,4)$ sql topology based on the $\left[\mathrm{M}(\mathrm{COO})_{2}\right]$ SBUs, while complex 4 has 2D sql layer motifs which aggregate into a $2 \mathrm{D}+2 \mathrm{D} \rightarrow 3 \mathrm{D}$ mutually inclined interpenetrated framework. The UV-vis absorption spectra of 1-4 are discussed. Moreover, complexes $\mathbf{3}$ and $\mathbf{4}$ exhibit intense fluorescence emission and $\mathbf{1}$ shows $\mathrm{CO}_{2}$ gas sorption property. The results imply that not only the $\mathrm{N}$-donor imidazolyl ligands as well as the carboxylate ligand possess variable coordination modes in construction of MOFs, but also show the nature of metal ions and reaction conditions play crucial roles in modulating the formation of the resulting coordination complexes; the combination of rigid $\mathrm{N}$-donor ligand with multi-carboxylate is a good choice for the construction of MOFs with specific structures and properties. 
Supplementary Materials: The following are available online at http:/ / www.mdpi.com/2073-4360/10/6/622/s1, Figure S1: TGA, Figure S2: PXRD, Table S1: Selected bond lengths and bond angles.

Author Contributions: W.-D.L. reviewed literature and performed the experiments. X.-Z.G. and Z.-Y.Z. carried out the measurements and analyzed the data. J.-L.L. assisted W.-D.L. to perform the experiment. S.-S.C. designed the experimental section, analyzed the data, and wrote the paper. All the authors reviewed and approved the paper.

Acknowledgments: We are grateful to the National Natural Science Foundation of China (Grant no. 21171040) and Natural Science Foundation of Colleges of Anhui Province (KJ2017ZD29) for their support and we are also grateful for the help from the Anhui Provincial Key Laboratory for Degradation and Monitoring of Pollution of The Environment.

Conflicts of Interest: The authors declare no conflicts of interest.

\section{References}

1. Zhu, L.; Liu, X.Q.; Jiang, H.L.; Sun, L.B. Metal-organic frameworks for heterogeneous basic catalysis. Chem. Rev. 2017, 117, 8129-8176. [CrossRef] [PubMed]

2. Schoedel, A.; Li, M.; Li, D.; O'Keeffe, M.; Yaghi, O.M. Structures of metal-organic framewroks with rod secondary building units. Chem. Rev. 2016, 116, 12466-12535. [CrossRef] [PubMed]

3. Bao, Z.; Xie, D.; Chang, G.; Wu, H.; Li, L.; Zhou, W.; Wang, H.; Zhang, Z.; Xing, H.; Yang, Q.; et al. Fine Ttuning and specific binding sites with a porous hydrogen-bonded metal-complex framework for gas selective separations. J. Am. Chem. Soc. 2018, 140, 4596-4603. [CrossRef] [PubMed]

4. Rieth, A.J.; Dincă, M. Controlled gas uptake in metal-organic frameworks with record ammonia sorption. J. Am. Chem. Soc. 2018, 140, 3461-3466. [CrossRef] [PubMed]

5. Zhao, D.; Liu, X.H.; Zhao, Y.; Wang, P.; Liu, Y.; Azam, M.; Al-Resayes, S.I.; Lu, Y.; Sun, W.Y. Luminescent $\mathrm{Cd}$ (II)-organic frameworks with chelating $\mathrm{NH}_{2}$ sites for selective detection of $\mathrm{Fe}(\mathrm{III})$ and antibiotics. J. Mater. Chem. A 2017, 5, 15797-15807. [CrossRef]

6. Chen, J.J.; Chang, Y.T.; Wu, C.J.; Hsu, Y.F.; Lin, C.H.; Proserpio, D.M.; Chen, J.D. Highly interpenetrated diamondoid nets of $\mathrm{Zn}(\mathrm{II})$ and $\mathrm{Cd}(\mathrm{II})$ coordination networks from mixed ligands. CrystEngComm 2012, 14, 537-543. [CrossRef]

7. Mori, W.; Sato, T.; Kato, C.N.; Takei, T.; Ohmura, T. Discovery and development of microporous metal carboxylates. Chem. Rec. 2005, 5, 336-351. [CrossRef] [PubMed]

8. Doonan, C.; Riccò, R.; Bradshaw, D.; Falcaro, P. Metal-organic frameworks at the biointerface: Synthetic strategies and applications. Acc. Chem. Res. 2017, 50, 1423-1432. [CrossRef] [PubMed]

9. Chen, W.; Wu, C. Synthesis, functionalization, and applications of metal-organic frameworks in biomedicine. Dalton Trans. 2018, 47, 2114-2133. [CrossRef] [PubMed]

10. Chu, Y.; Hou, J.; Boyer, C.; Richardson, J.J.; Liang, K.; Xu, J. Biomimetic synthesis of coordination network materials: Recent advances in MOFs and MPNs. Appl. Mater. Today 2018, 10, 93-105. [CrossRef]

11. Ye, R.P.; Zhang, X.; Zhang, L.; Zhang, J.; Yao, Y.G. Solvent and pH driven self-assembly of isomeric or isomorphic complexes: Crystal structure and luminescent change upon desolvation. Cryst. Growth Des. 2016, 16, 4012-4020. [CrossRef]

12. Chang, M.N.; Yang, X.K.; Chhetri, P.M.; Chen, J.D. Metal and ligand effects on the construction of divalent coordination polymers based on bis-pyridyl-bis-amide and polycarboxylate ligands. Polymers 2017, 9, 691. [CrossRef]

13. Zhang, Z.Y.; Xiao, L.; Chen, S.S.; Qiao, R.; Yang, S. A novel Zn(II) complex with 4-connected umc topology: Synthesis, crystal structure and luminescent property. Chin. J. Struct. Chem. 2017, 36, 819-824.

14. Zhang, Y.B.; Furukawa, H.; Ko, N.; Nie, W.; Park, H.J.; Okajima, S.; Cordova, K.E.; Deng, H.; Kim, J.; Yaghi, O.M. Introduction of functionality, selection of topology, and enhancement of gas adsorption in multivariate metal-organic framework-177. J. Am. Chem. Soc. 2015, 137, 2641-2650. [CrossRef] [PubMed]

15. Doonan, C.J.; Sumby, C.J. Metal-organic framework catalysis. CrystEngComm 2017, 19, 4044-4048. [CrossRef]

16. King, S.C.; Lin, R.B.; Wang, H.; Arman, H.D.; Chen, B. Two-dimensional metal-organic frameworks for selective separation of $\mathrm{CO}_{2} / \mathrm{CH}_{4}$ and $\mathrm{CO}_{2} / \mathrm{N}_{2}$. Mater. Chem. Front. 2017, 1, 1514-1519. [CrossRef]

17. Chang, Z.; Zhang, D.S.; Chen, Q.; Li, R.F.; Hu, T.L.; Bu, X.H. Rational construction of 3D pillared metal-organic frameworks: Synthesis, structures, and hydrogen adsorption properties. Inorg. Chem. 2011, 50, 7555-7562. [CrossRef] [PubMed] 
18. Zhou, H.; Chen, Q.; Yuan, A.H.; Zhou, H.B.; Shen, X.P.; Chen, L.; Song, Y. A series of lanthanide(III)-bpdo-octacyanotungstate(V) compounds (bpdo $=4,4^{\prime}$-Bipyridine-N, $\mathrm{N}^{\prime}$-dioxide) involving the structural transformation from ion pair to three-dimensional pillared layer via a two-dimensional layer. Cryst. Growth Des. 2017, 17, 6523-6530. [CrossRef]

19. Tehrani, A.A.; Ghasempour, H.; Morsali, A.; Makhloufi, G.; Janiak, C. Effects of extending the $\pi$-electron system of pillaring linkers on fluorescence sensing of aromatic compounds in two isoreticular metal-organic frameworks. Cryst. Growth Des. 2015, 15, 5543-5547. [CrossRef]

20. Lee, C.H.; Wu, J.Y.; Lee, G.H.; Peng, S.M.; Jiang, J.C.; Lu, K.L. Correlation of mesh size of metal-carboxylate layer with degree of interpenetration in pillared-layer frameworks. Cryst. Growth Des. 2014, 14, 5608-5616. [CrossRef]

21. Chen, S.S.; Qiao, R.; Sheng, L.Q.; Zhao, Y.; Yang, S.; Chen, M.M.; Liu, Z.D.; Wang, D.H. Cadmium(II) and zinc(II) complexes with rigid 1-(1H-imidazol-4-yl)-3-(4H-tetrazol-5-yl) benzene and varied carboxylate ligands. CrystEngComm 2013, 15, 5713-5725. [CrossRef]

22. Chen, S.S.; Chen, M.; Takamizawa, S.; Chen, M.S.; Su, Z.; Sun, W.Y. Temperature dependent selective gas sorption of the microporous metal-imidazolate framework $[\mathrm{Cu}(\mathrm{L})]\left[\mathrm{H}_{2} \mathrm{~L}=1\right.$,4-di $(1 \mathrm{H}$-imidazol-4-yl)benzene]. Chem. Commun. 2011, 47, 752-754. [CrossRef] [PubMed]

23. Chen, S.S.; Chen, M.; Takamizawa, S.; Wang, P.; Lv, G.C.; Sun, W.Y. Porous cobalt(II)-imidazolate supramolecular isomeric frameworks with selective gas sorption property. Chem. Commun. 2011, 47, 4902-4904. [CrossRef] [PubMed]

24. Jiang, Z.Q.; Jiang, G.Y.; Hou, D.C.; Wang, F.; Zhao, Z.; Zhang, J. Urothermal synthesis of photoluminescent lanthanide-organic frameworks with unusual topologies. CrystEngComm 2013, 15, 315-323. [CrossRef]

25. He, Y.C.; Yang, J.; Kan, W.Q.; Ma, J.F. An ideal metal-organic rhombic dodecahedron for highly efficient adsorption of dyes in an aqueous solution. CrystEngComm 2013, 15, 848-851. [CrossRef]

26. Jia, J.H.; Athwal, H.S.; Blake, A.J.; Champness, N.R.; Hubberstey, P.; Schröder, M. Increasing nuclearity of secondary building units in porous cobalt(II) metal-organic frameworks: Variation in structure and $\mathrm{H}_{2}$ adsorption. Dalton Trans. 2011, 40, 12342-12349. [CrossRef] [PubMed]

27. Du, M.; Li, C.P.; Liu, C.S.; Fang, S.M. Design and construction of coordination polymers with mixed-ligand synthetic strategy. Coord. Chem. Rev. 2013, 257, 1282-1305. [CrossRef]

28. Sun, Y.X.; Sun, W.Y. Zinc(II)- and cadmium(II)-organic frameworks with 1-imidazole-containing and 1-imidazole-carboxylate ligands. CrystEngComm 2015, 17, 4045-4063. [CrossRef]

29. Chen, S.S.; Sheng, L.Q.; Zhao, Y.; Liu, Z.D.; Qiao, R.; Yang, S. Syntheses, structures, and properties of a series of polyazaheteroaromatic core-based $\mathrm{Zn}$ (II) coordination polymers together with carboxylate auxiliary ligands. Cryst. Growth Des. 2016, 16, 229-241. [CrossRef]

30. Qiao, R.; Chen, S.S.; Sheng, L.Q.; Yang, S.; Li, W.D. Syntheses, crystal structures, and properties of four complexes based on polycarboxylate and imidazole ligands. J. Solid State Chem. 2015, 228, 199-207. [CrossRef]

31. Chen, S.S.; Chen, Z.H.; Fan, J.; Okamura, T.-A.; Bai, Z.S.; Lv, M.F.; Sun, W.Y. Synthesis and characterization of metal complexes with mixed 4-imidazole-containing tripodal ligand and varied dicarboxylic acid. Cryst. Growth Des. 2012, 12, 2315-2326. [CrossRef]

32. Chen, S.S.; Zhao, Y.; Fan, J.; Okamura, T.-A.; Bai, Z.S.; Chen, Z.H.; Sun, W.Y. Construction of coordination frameworks based on 4-imidazolyl tecton 1,4-di(1H-imidazol-4-yl)benzene and varied carboxylic acids. CrystEngComm 2012, 14, 3564-3576. [CrossRef]

33. Ten Have, R.; Huisman, M.; Meetsma, A.; van Leusen, A.M. Novel synthesis of 4(5)-monosubstituted imidazoles via cycloaddition of tosylmethyl isocyanide to aldimines. Tetrahedron 1997, 53, 11355-11368. [CrossRef]

34. SAINT, version 6.2; Bruker AXS, Inc.: Madison, WI, USA, 2001.

35. G.M. Sheldrick SADABS; University of Göttingen: Göttingen, Germany, 1997.

36. G.M. Sheldrick, SHELXTL; Version 6.10; Bruker Analytical Xray Systems: Madison, WI, USA, 2001.

37. Spek, A.L. Single-crystal structure validation with the program PLATON. J. Appl. Crystallogr. 2003, 36, 7. [CrossRef]

38. Chen, S.S.; Lv, G.C.; Fan, J.; Okamura, T.-A.; Chen, M.; Sun, W.Y. Entangled coordination frameworks with 1,4-di(1H-imidazol-4-yl)benzene. Cryst. Growth Des. 2011, 11, 1082-1090. [CrossRef] 
39. Arici, M.; Yeşilel, O.Z.; Taş, M.; Demiral, H. $\mathrm{CO}_{2}$ and iodine uptake properties of Co(II)-coordination polymer constructed from tetracarboxylic acid and flexible bis(imidazole) linker. Cryst. Growth Des. 2017, 17, 2654-2659. [CrossRef]

40. Wang, C.Y.; Wilseck, Z.M.; LaDuca, R.L. 1D + 1D $\rightarrow$ 1D polyrotaxane, 2D + 2D $\rightarrow$ 3D interpenetrated, and 3D self-penetrated divalent metal terephthalate bis(pyridylformyl)piperazine coordination polymers. Inorg. Chem. 2011, 50, 8997-9003. [CrossRef] [PubMed]

41. Xu, B.; Lü, J.; Cao, R. Anion-assisted structural variation of cadmium coordination polymers: From 2D $\rightarrow$ 3D inclined polycatenation to 2D $\rightarrow$ 3D polythreading. Cryst. Growth Des. 2009, 9, 3003-3005. [CrossRef]

42. Yang, Y.J.; Wang, M.J.; Zhang, K.L. A novel photoluminescent Cd(II)-organic framework exhibiting rapid and efficient multi-responsive fluorescence sensing for trace amounts of $\mathrm{Fe}^{3+}$ ions and some NACs, especially for 4-nitroaniline and 2-methyl-4-nitroaniline. J. Mater. Chem. C 2016, 4, 11404-11418. [CrossRef]

43. Han, L.L.; Wang, S.N.; Jagličić, Z.; Zeng, S.Y.; Zheng, J.; Li, Z.H.; Chen, J.S.; Sun, D. Synthesis, structural versatility and magnetic properties of a series of copper(II) coordination polymers based on bipyrazole and various dicarboxylate ligands. CrystEngComm 2015, 17, 1405-1415. [CrossRef]

44. Nath, J.K.; Mondal, A.; Powell, A.K.; Baruah, J.B. Structures, Magnetic Properties, and Photoluminescence of Dicarboxylate Coordination Polymers of Mn, Co, Ni, Cu Having N-(4-Pyridylmethyl)-1,8-naphthalimide. Cryst. Growth Des. 2014, 14, 4735-4748. [CrossRef]

45. Bordiga, S.; Lamberti, C.; Ricchiardi, G.; Regli, L.; Bonino, F.; Damin, A.; Zecchina, A. Electronic and vibrational properties of a MOF-5 metal-organic framework: ZnO quantum dot behavior. Chem. Commun. 2004, 20, 2300-2301. [CrossRef] [PubMed]

46. Alvaro, M.; Carbonell, E.; Ferrer, B.; Llabrés, F.X.; Xamena, I.; Garcia, H. Semiconductor Behavior of a Metal-Organic Framework (MOF). Chem. Eur. J. 2007, 13, 5106-5112. [CrossRef] [PubMed]

47. Su, J.; Yao, L.; Zhao, M.; Wang, H.; Zhang, Q.; Cheng, L.; Tian, Y. Structural induction effect of a zwitterion pyridiniumolate for metal-organic frameworks. Inorg. Chem. 2015, 54, 6169-6175. [CrossRef] [PubMed]

48. Wang, C.C.; Ke, S.Y.; Cheng, C.W.; Wang, Y.W.; Chiu, H.S.; Ko, Y.C.; Sun, N.K.; Ho, M.L.; Chang, C.K.; Chuang, Y.C.; et al. Four mixed-ligand Zn(II) three-dimensional metal-organic frameworks: Synthesis, structural diversity, and photoluminescent property. Polymers 2017, 9, 644. [CrossRef]

49. Zhu, M.A.; Guo, X.Z.; Chen, S.S. Synthesis, crystal structure and luminescent property of a Zn(II) complex based on 4-imidazole-carboxylate ligand. Chin. J. Struct. Chem. 2017, 36, 1348-1354.

50. Shi, Z.; Pan, Z.; Jia, H.; Chen, S.; Qin, L.; Zheng, H. Zn(II)/Cd(II) terephthalate coordination polymers incorporating bi-, tri-, and tetratopic phenylamine derivatives: Crystal structures and photoluminescent properties. Cryst. Growth Des. 2016, 16, 2747-2755. [CrossRef]

51. Liu, Y.Y.; Liu, H.Y.; Ma, J.F.; Yang, Y.; Yang, J. Syntheses, structures and photoluminescent properties of Zn(II) and $\mathrm{Cd}(\mathrm{II})$ coordination polymers with flexible tripodal triazole-containing ligands. CrystEngComm 2013, 15, 1897-1907. [CrossRef]

52. Han, Y.F.; Zhou, X.H.; Zheng, Y.X.; Shen, Z.; Song, Y.; You, X.Z. Syntheses, structures, photoluminescence, and magnetic properties of nanoporous 3D lanthanide coordination polymers with $4,4^{\prime}$-biphenyldicarboxylate ligand. CrystEngComm 2008, 10, 1237-1242. [CrossRef]

53. Wang, X.; Qin, C.; Wang, E.; Li, Y.; Hao, N.; Hu, C.; Xu, L. Syntheses, structures, and photoluminescence of a novel class of $\mathrm{d}^{10}$ metal complexes constructed from pyridine-3,4-dicarboxylic acid with different coordination architectures. Inorg. Chem. 2004, 43, 1850-1856. [CrossRef] [PubMed]

54. Hua, J.A.; Zhao, Y.; Liu, Q.; Zhao, D.; Chen, K.; Sun, W.Y. Zinc(II) coordination polymers with substituted benzenedicarboxylate and tripodal imidazole ligands: Syntheses, structures and properties. CrystEngComm 2014, 16, 7536-7546. [CrossRef]

55. Li, Y.W.; Ma, H.; Chen, Y.Q.; He, K.H.; Li, Z.X.; Bu, X.H. Structure modulation in Zn(II)-1,4-bis(imidazol-1-yl) benzene frameworks by varying dicarboxylate anions. Cryst. Growth Des. 2012, 12, 189-196. [CrossRef]

56. Sun, Y.; Sun, Y.; Zheng, H.; Wang, H.; Han, Y.; Wang, L. Four calcium(II) coordination polymers based on 2,5-dibromoterephthalic acid and different N-donor organic species: Syntheses, structures, topologies, and luminescence properties. CrystEngComm 2016, 18, 8664-8671. [CrossRef]

57. Gu, Z.G.; Liu, Y.T.; Hong, X.J.; Zhan, Q.G.; Zheng, Z.P.; Zheng, S.R.; Li, W.S.; Hu, S.J.; Cai, Y.P. Construction of metal-imidazole-based dicarboxylate networks with topological diversity: Thermal stability, gas adsorption, and fluorescent emission properties. Cryst. Growth Des. 2012, 12, 2178-2186. [CrossRef] 
58. Zhang, L.Y.; Zhang, J.P.; Lin, Y.Y.; Chen, X.M. Syntheses, structures, and photoluminescence of three coordination polymers of cadmium dicarboxylates. Cryst. Growth Des. 2006, 6, 1684-1689. [CrossRef]

59. Zhang, M.; Feng, G.; Song, Z.; Zhou, Y.P.; Chao, H.Y.; Yuan, D.; Tan, T.T.; Guo, Z.; Hu, Z.; Tang, B.Z.; et al. Two-dimensional metal-organic framework with wide channels and responsive turn-on fluorescence for the chemical sensing of volatile organic compounds. J. Am. Chem. Soc. 2014, 136, 7241-7244. [CrossRef] [PubMed]

60. Ye, R.P.; Zhang, X.; Zhai, J.Q.; Qin, Y.Y.; Zhang, L.; Yao, Y.G.; Zhang, J. N-donor ligands enhancing luminescence properties of seven $\mathrm{Zn} / \mathrm{Cd}(\mathrm{II}) \mathrm{MOF}$ based on a large rigid $\pi$-conjugated carboxylate ligand. CrystEngComm 2015, 17, 9155-9166. [CrossRef]

61. Yang, D.L.; Zhang, X.; Yao, Y.G.; Zhang, J. Structure versatility of coordination polymers constructed from a semirigid ligand and polynuclear metal clusters. CrystEngComm 2014, 16, 8047-8057. [CrossRef]

62. Liu, Y.Y.; Ma, J.F.; Yang, J.; Ma, J.C.; Su, Z.M. Versatile frameworks constructed from divalent metals and 1,2,3,4-butanetetracarboxylate anion: Syntheses, crystal structures, luminescence and magnetic properties. CrystEngComm 2008, 10, 894-904. [CrossRef]

63. Chen, M.S.; Chen, M.; Okamura, T.-A.; Sun, W.Y.; Ueyama, N. Porous zinc(II) frameworks with 5-(isonicotinamido)isophthalate: Syntheses, structures and properties. Microporous Mesoporous Mater. 2011, 139, 25-30. [CrossRef]

64. Bhunia, A.; Vasylyeva, V.; Janiak, C. From a supramolecular tetranitrile to a porous covalent triazine-based framework with high gas uptake capacities. Chem. Commun. 2013, 49, 3961-3963. [CrossRef] [PubMed]

65. Mondal, S.S.; Dey, S.; Baburin, I.A.; Kelling, A.; Schilde, U.; Seifert, G.; Janiak, C.; Holdt, H.-J. Syntheses of two imidazolate-4-amide-5-imidate linker-based hexagonal metal-organic frameworks with flexible ethoxy substituent. CrystEngComm 2013, 15, 9394-9399. [CrossRef]

(C) 2018 by the authors. Licensee MDPI, Basel, Switzerland. This article is an open access article distributed under the terms and conditions of the Creative Commons Attribution (CC BY) license (http://creativecommons.org/licenses/by/4.0/). 